\title{
The long and winding road: Routine creation and replication in multi-site organizations
}

\author{
Andrew Davies $^{\mathrm{a}, *}$, Lars Frederiksen ${ }^{\mathrm{b}}$, Eugenia Cacciatori ${ }^{\mathrm{c}}$, Andreas Hartmann ${ }^{\mathrm{d}}$ \\ a The Bartlett Faculty of the Built Environment, University College London, 1-19 Torrington Place, London WC1E 7HB, United Kingdom \\ b Department of Management, Aarhus University, BSS, 8210, Aarhus V, Denmark \\ c Cass Business School, City, University of London, London EC1Y 8TZ, United Kingdom \\ ${ }^{\mathrm{d}}$ Faculty of Engineering Technology, Department of Construction Management \& Engineering, University of Twente, 7500 AE Enschede, The Netherlands
}

\section{A R T I C L E I N F O}

\section{Keywords:}

Routines

Capabilities

Creation

Replication

Organizational hierarchy

\begin{abstract}
A B S T R A C T
Prior research on organizational routines in the 'capabilities' literature has either studied how new routines are created during an exploratory process of variation and selection or how existing routines are replicated during a phase of exploitation. Few studies have analyzed the life cycle of new routine creation and replication as an integrated process. In an in-depth case study of England's Highways Agency, this paper shows that the creation and replication of a new routine across multiple sites involves four sequential steps: envisioning, experimenting, entrenching and enacting. We contribute to the capabilities research in two ways: first, by showing how different organizational levels, capabilities and logics (cognitive and behavioural) shape the development of new routines; and second, by identifying how distinct evolutionary cycles of variation and selective retention occur during each step in the process. In contrast with prior research on replication as an exact copy of a template or existing routine, our study focuses on the replication of an entirely new routine (based on novel principles) that is adapted to fit local operational conditions during its large-scale replication across multiple sites. We draw upon insights from adjacent 'practice research' and suggest how capabilities and practice studies may complement each other in future research on the evolution of routines.
\end{abstract}

\section{Introduction}

Routines are defined as the "regular and predictable behavioural patterns of firms" (Nelson and Winter, 1982: 14). Organizations learn and adapt to the environment by encoding inferences from history into routines that guide behaviour (Levitt and March, 1988). Routines serve as stores of organizational memory, skills and tacit knowledge (Nelson and Winter, 1982; Cohen and Bacdayan, 1994) and are conceived as the building blocks of organizational capabilities (Winter, 1995; Felin et al., 2012). Organizations develop, stabilize and follow routines over extended periods of time and adapt to a changing environment by reconfiguring routines, creating new ones and using them consistently across organizational sites (Zollo and Winter, 2002).

In this paper we identify and analyze how new routines are intentionally created and reproduced with some degree of consistency and uniformity across multiple sites in an organization. Since Nelson and Winter's (1982) foundational work, research on routines has divided into two streams: the capabilities and practice perspectives (Parmigiani and Howard-Grenville, 2011). Capabilities research treats routines as whole entities and investigates how firms manage a portfolio of routines to achieve competitive advantage. Within this stream, research has either studied how dynamic capabilities are deployed in the search for new routines (e.g. Teece et al., 1997; Zollo and Winter, 2002) or how stable routines are replicated across multiple sites (Winter and Szulanski, 2001; Szulanski and Jensen, 2006; Winter et al., 2012). With its focus on the internal dynamics of routines, practice research shows how routines, once conceived as stable, can be a source of flexibility and change when performed by agents, but has paid less attention to how entirely new routines are created (Obstfeld, 2012; Feldman et al., 2016; Dionysiou and Tsoukas 2013; Salvato and Rerup, 2018).

Overall, surprisingly little research attempts to understand how the creation and replication of new routines is conducted as an integrated process over time (Gupta et al., 2015). Identifying this process is important as part of current research efforts to understand how routines come into being and stabilize (Obstfeld, 2012; Feldman et al., 2016, Dionysiou and Tsoukas 2013) and how routines are assembled into capabilities (Eggers and Kaplan, 2013). In addressing this issue, we

\footnotetext{
* Corresponding author.

E-mail addresses: a.c.davies@ucl.ac.uk (A. Davies), L.Frederiksen@mgmt.au.dk (L. Frederiksen), eugenia.cacciatori@city.ac.uk (E. Cacciatori), a.hartmann@ctw.utwente.nl (A. Hartmann).
} 
adopt a capabilities perspective because we are interested in understanding how new routines - treated as whole entities - can be targets for managerial interventions and intentionally developed to achieve an organization's strategic objectives (Nelson and Winter, 1982; Winter and Szulanski, 2001; Zollo and Winter, 2002; Levinthal and Marino, 2015)

In capabilities research, the evolution of new routines occurs when organizations generate new patterns of action and selectively retain the most successful elements (Nelson and Winter, 1982; Zollo and Winter, 2002). Zollo and Winter (2002) developed an evolutionary model of variation, internal selection, replication and retention showing how routines emerge and stabilize over time. This evolutionary process takes place within a 'dual-routines' structure (Nelson and Winter, 1982; Zollo and Winter, 2002): senior managers employ dynamic capabilities (higher-order routines) in the systematic search to change, create and replicate 'lower-order' operational routines (e.g. Teece et al., 1997; Zollo and Winter, 2002). Despite these important theoretical advances, however, few empirical studies examine how new routines are created in contexts that require their 'rapid' reproduction across sites.

Building on Zollo and Winter's (2002) model and other streams of capabilities research, we identify the specific organizational processes involved in the development and reproduction of new routines. In contrast with the traditional conceptualization of replication as an exact copy of an historical template or existing routine with high fidelity to the original as often occurs in industries such as banking or retailing (Winter and Szulanski, 2001), our study focuses on the uniform and consistent reproduction of an entirely new routine based on novel principles (Baden-Fuller and Winter, 2005) that is adapted to fit local operational conditions during its large-scale replication across multiple sites (Jonsson and Foss, 2011). Our research responds to calls for 'multilevel research' by showing how the process is shaped by different levels - strategic and operational - in an organizational hierarchy (Salvato and Rerup, 2011).

To address our research question we carried out an in-depth case study of how a large public-sector organization - England's Highways Agency - developed and implemented a new routine across multiple sites responsible for maintaining England's network of highways and trunk roads. We contribute to capabilities research on routines by providing a more fine-grained account of the specific processes involved in the life cycle of new routine creation and replication. Our model shows how actors working in different organizational levels (strategic and operational) interact during key phases (exploration and exploitation) in the process. We identify four sequential steps from the original decision to introduce a new routine to its widespread implementation across multiple sites: envisioning, experimenting, entrenching and enacting. Managers working in strategic and operational units perform distinct steps in the process as they navigate the long and uncertain path from routine creation to replication. By investigating how evolutionary processes occur in an empirical study, we show that there is no one-to-one correspondence between broad-level stages of variation, selection and retention and the specific steps and activities undertaken in actual practice.

The paper is organized as follows. Section 2 reviews the literature providing alternative conceptualizations of how routines are created and replicated as an organizational process; Section 3 describes our method and data; Section 4 introduces our research setting; Section 5 presents our findings; Section 6 identifies our contribution to research on routine development and offers suggestions for future research; and Section 7 provides a summary of our research.

\section{The creation and replication of organizational routines}

\subsection{Evolutionary theory of routines and capabilities}

Building on the work of the 'Carnegie School' (March and Simon, 1958; Cyert and March, 1963; Gavetti et al., 2007), Nelson and Winter
(1982) developed the concept of routine as the basic unit of analysis in an evolutionary theory of organizational change by natural selection. Nelson and Winter (1982) focused on the stable, predictable and learned 'behavioural' patterns of routines, whereas the Carnegie School emphasized the 'cognitive' decision rules, standardized operating procedures and other mental models that guide routine behaviour (Becker 2004; Salvato and Rerup, 2011). Nelson and Winter (1982) identified how organizations search and selectively retain entirely new routines when prevailing ones no longer provide an adequate response to environmental pressures by following a problem-solving sequence: "select element, test for desired attributes, terminate with success if attributes are present, select next element if they are not" (Nelson and Winter, 1982: 132).

The distinction between routines conceived as cognitive rules (Cyert and March, 1963) or behavioural regularities (Nelson and Winter, 1982) is avoided in more recent capabilities research showing how the two logics complement each other (Gavetti and Levinthal, 2000; Becker, 2004; Gavetti, 2005; Levinthal and Rerup, 2006; Eggers and Kaplan, 2013). Gavetti and Levinthal (2000) suggest that organizations engage in a cognitive and experiential search when existing routines are no longer appropriate in a changing environment and there is a perceived need to modify or replace them (Gavetti and Levinthal, 2000). Cognitive learning involves generating and assessing 'offline' analysis, experiments and consultations without implementing new practices or changing routines. Experiential learning occurs 'online' when actors engage in an activity in order to evaluate it and assess the performance of alternative practices, trial experiences and adjustments to routines. Whereas cognition refers to the 'forward-looking' rationality used to evaluate a broad set of alternatives, experiential learning depends on 'backward-looking' knowledge which accumulates as result of prior choices and behavioural patterns that change as a result of feedback from experience.

In evolutionary theory, routines are the building blocks of a firm's capabilities (Winter, 1995) located at two different levels of an organizational hierarchy. Influenced by Nelson and Winter's (1982) dualroutines framework, a distinction is made between dynamic capabilities at the strategic level and routines performed at the operational level (e.g. Helfat and Peteraf, 2003; Becker 2004; Helfat and Winter, 2011; Teece, 2007; Peteraf et al., 2013; Di Stefano et al., 2014). The collection of 'lower-order' routines performed to produce a product or provide a service are part of a firm's operational capabilities (Helfat and Peteraf, 2003; Helfat and Winter, 2011).

Dynamic capabilities are the 'higher-order routines' employed by top managers to intentionally build, integrate and reconfigure operating routines in response to a changing technology or market environment (Teece et al., 1997; Zollo and Winter, 2002; Winter, 2003; Knott, 2001; Easterby-Smith et al., 2009; Daneels, 2008, 2010; Ethiraj et al., 2005; Helfat and Winter, 2011) and select a routine for widespread replication (Winter and Szulanski, 2001; Teece, 2007). The duallevel distinction in capabilities research provides us with a broad framework to investigate how the process of routine creation and replication is shaped by different levels in an organizational hierarchy (Salvato and Rerup, 2011; Lazaric, 2011) - strategic and operational. Zollo and Winter (2002) provide an overall description of the process, but little research has attempted to investigate empirically how dynamic capabilities and operating routines interact in a hierarchical relationship during routine creation and stabilization.

\subsection{Routine creation}

In capabilities research, the creation of new routines is conceptualized as an evolutionary process of variation, selection and retention, which when consistently undertaken constitutes a dynamic capability. Zollo and Winter (2002) suggest that routines evolve through four stages in knowledge cycle.

First, in the generative variation stage, individuals or groups engage 
in an off-line cognitive process to generate new ideas and approach new challenges or existing problems in novel and creative ways. This involves responding to external stimuli (e.g. competitor's initiatives, normative changes and new discoveries) and internally generated information about the adequacy of an organization's existing routines in a changing environment. Second, in the internal selection stage the organization analyzes and debates the expected benefits and risks of the new ideas in relation to the shared understanding of the organization's previous experience and their potential for enhancing existing routines or creating new ones. Internal selection occurs when one variation is selected and others are eliminated. Third, in the replication stage, now performed online, the new operational routine or enhancement of an existing one is reproduced at relevant sites within the organization. Fourth, in the retention stage, the new information created when new routines are employed in diverse contexts can initiate a new stage of variation in the knowledge cycle. Retention occurs when selected operating routines are enacted across multiple sites and repeated on future occasions.

While conceptually separated into stages, in practice the four activities are connected by a chain of feedback loops in a recursive cycle of knowledge development (Zollo and Winter, 2002). The four stages of evolution transition over time, in March's (1991) terms, from a phase of exploration to a phase of exploitation (Zolo and Winter, 2002: 344). The initial stages of generative variation and internal selection - or exploration - depend on deliberate and intentional cognitive forwardlooking efforts to generate a range of novel ideas and intuitions and select the most appropriate ones through various evaluations and assessments. The latter stages of replication and retention - or exploitation - depend to a greater extent on backward-looking experiential mechanisms to replicate the new routines in diverse contexts and incorporate them in recurring operational activities. In addition, in recent work, Levinthal and Marino (2015) discuss a double-level selection process, in which an organization selects both at the level of broadly different classes of routines and at the level of variation in the characteristics of each selected class.

\subsection{Routine replication}

While the broad evolutionary process of variation and selective retention has received a great deal of attention in the capabilities literature, there has been little empirical research identifying how this takes place in practice, particularly during the generation of new routines prior to replication (Gupta et al., 2015). Replication occurs when routines are copied and reproduced across multiple sites within organizations. Based on the assumption that an existing routine or historical template is available for selection and retention (Winter and Szulanski, 2001), studies of replication neglect to consider the possibility that a new routine - in the absence of an existing template - is deliberately created and prepared for widespread replication.

A transition from exploration to exploitation underpins Winter and Szulanski's (2001) influential model of replication. A phase of exploration occurs when successful attributes of knowledge comprised of a complex set of interdependent routines are discovered, fine-tuned and refined. A subsequent phase of exploitation takes place when the replicator abandons further efforts to refine the new practice, decides to stabilize the format (or freeze the design), ignores traits that fail to add value, and initiates large-scale replication of the selected routine in many local units, often facing resistance from locally autonomous agents.

A 'guiding example' or 'historical template' is used as the basis for a replicated routine. The template captures all the information that contributes to the success of the replicated routine (Winter and Szulanski, 2001: 733). However, not every replication is guided by a template. Replicators may completely ignore or bypass reference to existing working examples in an attempt to create a new example based on "nothing but plans, or even nothing but ideas, to guide the effort"
(Winter and Szulanski, 2001: 736). Baden-Fuller and Winter (2005) considered how replication occurs when organizations 'replicate by principles' with no direct reference to a working example or existing template. Whereas templates consist of knowledge of 'how' things work, principles refer to causal explanations about 'why' certain things work. But bypassing a template is considered risky because of the unanticipated problems that can arise when implementing complex and causally ambiguous routines in new settings. For this reason, organizations are advised to copy the template 'exactly', before attempting modifications and adjustments to the context of each local operating unit (Jensen and Szulanski, 2007; McDonald, 1998; Szulanski and Jensen, 2006, 2008; Winter and Szulanski, 2001).

The transition between phases is a critical period when the replicator depends on the dynamic capabilities of a central strategic unit to recreate complex, imperfectly understood and partially tacit knowledge in carefully-selected sites in preparation for large-scale replication (Winter and Szulanski, 2001: 731). This strategic organization is responsible for developing a repository of templates, gathering feedback on each successive replication, acquiring a detailed understanding of the existing site-specific tasks, skills, and tasks performed by local operational units, and identifying which new procedures will enable those local units to replicate the new operational routine. The strategic unit requires dynamic capabilities to capture value from replication during the exploitation phase by supporting the expansion of a standardized practice and understanding how tacit and highly complex routines provide a foundation for learning and systematic replication (Teece et al., 1997: 525).

The assumption that a template should not be modified by operational units during the process of replication (Szulanski and Jensen, 2006, 2008; Winter et al., 2012) is questioned by Jonsson and Foss (2011) who found that copy exact replication is not always appropriate. In a study of IKEA Jonsson and Foss developed a 'flexible replication' process. The model distinguishes between central features that need to be copied exactly and peripheral features that can be adapted to local markets. This process involves local adaptation of the original template and ongoing iterations between exploration and exploitation. Importantly, knowledge moving in the reverse direction from operational to strategic units may also shape the evolution of routines and their adaptation to local contexts. This resembles the findings of an adjacent stream of research concerned with how management practices are varied and adapted to fit the particular context within which they are adopted (Ansari et al., 2014; Peeters et al., 2014). D'Adderio (2014) found that organizations deal with the conflicting goals and pressures to copy exactly (replication) and change (innovation) by separating the two processes and enacting them at different times.

\subsection{Insights from practice research}

Responding to recent calls to build connections between capabilities and practice research on routines (Parmigiani and Howard-Grenville, 2011; Howard-Grenville et al., 2016), we identify important insights that can help to illuminate the processes investigated in this paper. Focusing on the inner workings of routines, practice research identifies how routines change as people enact them (Feldman, 2000; Feldman and Rafaeli, 2002; Feldman and Pentland, 2003; Pentland et al., 2012), how variation and selective retention take place at the level of the individual actions that comprise a routine (Feldman and Pentland, 2003) and how the cognitive or behavioural dimensions of routines, discussed earlier, are entwined in actual practice (Feldman and Pentland, 2003; Salvato and Rerup, 2011; Howard-Grenville et al., 2016). Whereas 'performative aspects' are the behavioural actions accomplished by people at a particular time and in a specific place, 'ostensive aspects' are cognitive models, abstract understandings and rules for enacting the routine (Feldman and Pentland, 2003).

Recent research addresses "where routines come from" (Feldman et al., 2016; Howard-Grenville et al., 2016) including the processes of 
variation and retention involved in the creation and intentional development of routines (Dittrich and Seidl, 2018). Pentland et al. (2012) develop a simulation model showing how new routines are generated over time through a dynamic process of variation and selective retention. Several scholars identify the role of trial-and-error learning and sequences of action involved in the creation of routines (Lazaric and Denis, 2005; Rerup and Feldman, 2011; Dionysiou and Tsoukas, 2013).

In practice research, routine creation is conceived as an emergent process resulting from the repetitive patterns of action and internal dynamics of routines. Building on the distinction between a routine's ostensive and performative aspects, Obstfeld (2012) identifies the emergent and deliberate action associated with two alternative trajectories of routine development. A routine trajectory is based on past repetition and the stable pattern of action undertaken to keep work on track by addressing minor contingencies and adjustments. A 'creative project' trajectory is initiated to get new things done - or create new routines - by envisioning a new end state and pursuing that objective through emergent action.

Practice research explains how artifacts provide the context within which routines develop, including the ostensive and performative aspects (Howard-Grenville and Rerup, 2016). Standardized operating procedures, software tools, checklists, templates and other written documentation are artifacts of the ostensive aspect of routines. But the ostensive aspect is not identical with an artifact because it also includes the subjective understandings and tacit knowledge of the actors involved. Indeed, some routines do not have artifacts because they are based entirely on abstract rules and nonformal representations. Artifacts may influence the emergence routines by "stabilizing existing action patterns, or providing the glue that can hold patterns together" (D'Adderio, 2011: 1). Recent research considers the role of artifacts in the development of new routines (Cacciatori, 2012) and how artifacts are intentionally designed to shape routine dynamics (Glaser, 2017). D'Adderio (2014) shows how artifacts are used during the transfer phase of replication to provide consistency and modified in the posttransfer phase to facilitate variation and adaptation. Finally, Seele and Grand (2016) and Spee et al. (2016) show how artifacts perform a key role in supporting the interconnection among different routines.

Contributions from practice research shed light on the patterns of action and artifacts involved in the emergence and persistence of new routines. However, there is little understanding of how artifacts and routines work together in an overall organizational process and how the intention to create new routines to achieve an organization's strategic objectives shapes their development over time.

\subsection{Constructs informing our research}

Our review of the literature identifies the key constructs required to answer our research question: How are new routines created and replicated across multiple sites in organizations? By drawing together these different strands of capabilities research we are able to consider how the creation and replication of new routines can be depicted as a process involving a life cycle from early exploration to widespread exploitation. By examining the dual-level structure of routine development, we can identify how the development of new routines is shaped by different levels in the organizational hierarchy and their associated behavioural and cognitive rationalities (Salvato and Rerup, 2011). Strategic units employ high-order dynamic capabilities to develop new routines and select templates for widespread replication. Managers in strategic units primarily depend on a forward-looking cognitive reasoning to envision a future end state, creatively develop new principles and select templates for widespread replication. Operational units experiment with new routines in selected trials and subsequently adapt standardized practices during a process of implementation in multiple sites. Managers in operational units depend on a backward-looking experiential reasoning based on past routines, experience and feedback gained from the performance of routines.
Practice research suggests that artifacts, such as written procedures and rules, shape the evolution of routines from their creation to replication across multiple sites.

\section{Research methods}

\subsection{Data gathering}

We conducted a case-study of England's Highways Agency (HA) to explore our research question: How do organizations create and replicate new routines across multiple sites? Since its foundation in 1994, the HA has systematically developed new generations of new contracts and written procedures - each intentionally designed and used to create and implement a new routine - to improve the procurement and management of the maintenance of highways and trunk roads across its geographical regions.

We initiated our research by holding high-level discussions with senior HA managers to define the scope of the research. Our close interaction with practitioners in HA and its contractual partners provided us with a rich and detailed appreciation of the context within which the work was undertaken (Barley and Kunda, 2001). The main source of data collection was 44 semi-structured retrospective and real-time interviews (60-180 min) using an open-ended interview protocol over a period of 20 months (March 2007-November 2008). We produced a case study as a narrative to capture the findings from our interviews which we discussed with key informants. In addition, we conducted two interviews with our main point of contact in HA (2010) to explore the validity and usefulness of our conceptual findings - the process model of routine creation and replication described below (Lincoln and Guba, 1985). While undertaking the interviews for our fieldwork we participated in workshops and conferences, and gathered and analyzed documentary material addressing the HA's strategy, procurement and contractual activities.

Informants were asked questions about their role and responsibilities in the HA and its partner organizations (e.g. new joint ventures), focusing on the activities involved in creating, developing, and implementing the new maintenance contracts. Interviews addressed the skills, experience, organizational structures and support needed to perform new activities and identified the sequence of events, activities, and decisions to improve highway maintenance performance. We encouraged informants to illustrate their statements with examples from various situations and specific events. We updated our interview protocol regularly so that it was firmly anchored in our emergent findings and included more specific details about the ongoing process of routine creation, development and implementation as our understanding deepened. In this way, we moved from a more abstract understanding towards a more concrete identification of the managerial actions and organizational units involved during particular stages in the process of new routine development. Our data collection was brought to a close when we experienced conceptual saturation.

Interviews took place on site at the HA offices in London, Bristol, and Birmingham. We relied on purposeful sampling and the snowballing technique (Lincoln and Guba, 1985; Kumar et al., 1993) to identify the appropriate informants. Interviews were undertaken with managers in the strategy and central procurement units responsible for developing the new procurement methods and with managers at the operational level in a selected HA geographical areas responsible for developing the routines required to enact the new maintenance contracts. We interviewed HA board members, the CEO, directors (e.g., finance, HR, and network strategy) because they had a deep knowledge of the organization's history and were key decision makers shaping the organization's future strategy for procurement. We interviewed staff in the central procurement department (which, in our setting, was a key strategic unit) to understand the role of contracts and written guidelines in the development and implementation of the new routines across multiple sites. Interviews in the operational units were conducted with 
HA directors of regional offices (the people responsible for developing and implementing the actual routines) and members of the operational teams including staff working for the HA and various contractors. Recorded and transcribed for analysis, interviews were undertaken by two authors (and on several occasions a third author) and immediately followed by a debriefing and initial data analysis.

To increase confidence in the validity of our findings, we supplemented data gathering with focus-group meetings where we discussed our preliminary results, initial hypotheses, and conceptual frameworks. These sessions provided further information and documentation about the HA's strategies, project reports, minutes, and news briefs. We attended four workshops where we listened to presentations about the new maintenance contracts. Our participation provided access to informal after-work sessions where our findings were further discussed and analyzed by HA staff. Such observations allowed for greater reflexivity in making sense of our interview material and assisted our interpretation of how the organizations progressed over time (Barley and Kunda, 2001). Because the HA was publicly owned, it was legally required to be transparent and accountable for its actions, providing us with access to the large amount of rich secondary source documentation available in the public domain (Suddaby, 2006).

\subsection{Data analysis}

As we were interested in routine creation and replication as an integrated process, we adopted Langley's (1999) methodology. Using interviews and documentary sources, we reconstructed a broad narrative of how the HA developed and implemented the new routines across its regions. Adopting Strauss and Corbin's (1990) procedure, we manually open coded the interview transcripts and other descriptive materials into initial concepts. By iterating between coding, data collection, and relevant literature, we were able to substantiate initial concepts. We used axial coding to focus on one category at a time in order to consider the relationships between core concepts (Strauss, 1987: 32). Fig. 1 shows our data structure and Table 1 provides examples of how interview quotes were coded and grouped into first and second-order themes. These representative quotes are illustrative examples of corroborated findings confirmed by multiple respondents.

During the open coding process, we selected certain terms and phrases to represent the meanings various groups attached to activities involved in routine creation and development, including the different types of skills and competences employed, and actions related to specific events (Van Maanen, 1979). These codes (such as how contracts were prepared) emerged as we engaged closely with the research setting. As shown in the literature review, there is a well-developed body of literature on the evolution of routines and their replication. This body of knowledge provided us with broad concepts that were useful for engaging in a dialogue with extant work. In this phase, we used theory to identify broad concepts and sensitize us to emerging themes in the data, rather than as a means to construct specific, testable hypotheses (Charmaz, 2014; Kelle, 2005). Therefore a few of the nine first-order codes corresponded to theoretically relevant concepts - such as capturing and sharing knowledge.

Our discovery that the creation and replication of new routines follows distinct phases of progression (as we show in the Findings section) provided our primary theoretical breakthrough. This was then taken to the next step in data collection for checking and revision. In a structured process, we developed our second-order conceptual coding (Gioia et al., 2010; Corley and Gioia, 2004; Gioia et al., 2013), linking our empirical findings to conceptual themes and overarching dimensions identified in our initial and ongoing literature review including the central idea guiding our research. The argument in capabilities research that new routines evolve through a life cycle from exploration to exploitation and are shaped by two levels in an organizational hierarchy (the strategic and operational units) helped us identify the four-step sequence of managerial actions involved in the creation and replication of new routines. The conceptualization of routines in practice research as an ensemble of actors and artifacts helped us understand the role of contracts as artifacts or written guidelines without which the new routines could not emerge.

Moving from first to higher-order codes required an assessment of how statements in each of the codes could be grouped into themes and, eventually, aggregate dimensions, such as exploring and exploiting (Gioia et al., 2013: 20-22). As an example of this process, in the 'Developing procurement principles' code we had quotes such as:

"Traditionally in government that's always been lowest price...but clearly that was flawed, because it just drove down tender prices until they were unsustainable, and then you'd got all the contractual claims. So how could you develop? Our thought process was how do you develop a whole series of processes that will give, in effect, the chief executive, the chief accounting officer, the assurances that you are appointing the best suppliers to carry out the outsourced work, and at the same time it will be affordable, and you will improve budgeting certainty?...So that, that was a huge challenge" (HA interview 2008).

In our data, we found many similar quotes highlighting how interviewees in the strategic unit were influenced by a forward-looking cognitive logic of envisioning a desired end state and identifying the novel ideas and processes required to achieve it. This led to the development of an 'envisioning' second order code. Similarly, in 'Transforming working behavior':

"I think there are certain things within contracts you can interpret without actually changing the letter of them, and that can translate through to quite a significant difference in approach out on the ground, but accepting, of course, you know, you only kind of do that if it's actually...fulfilling the outcome that you want." (HA interview 2010).

We discovered many quotes showing how the actions of managers in the operational units working with the new contracts were shaped by a backward-looking behavioural logic of modifying their existing routines, experimenting with new approaches and engaging in the trial and error learning required to use and implement the new contract.

The analysis of the interviews was complemented by a review of HA publications and government reports on best practice in innovation, contracts, and project management (see Appendix A for a list of formal publications). These archival data sources were used for triangulation purposes (Jick, 1979) and in combination with information gathered from our interviews helped us to identify the sequence of events associated with the introduction of the new maintenance contracts.

\section{Research setting: innovation in road maintenance}

The HA was established in 1994 as an executive agency of the UK government's Department for Transport (DfT). In 2008, when we conducted most our original research, the HA was responsible for managing the construction, maintenance and operations of England's $10,500 \mathrm{~km}$ of roads and motorways. It provided $95 \%$ of its services through external consultants and contractors and employed around 2700 staff in an organization with one corporate centre (London), 7 regional control centres, a national control centre, and 14 regional areas. On 1st April, 2015, the HA became a government-owned company called Highways England with power to direct its operations, while remaining fully accountable to the UK government.

Since its foundation, the performance of the HA has been scrutinized, audited, and reviewed by various government bodies and industry reports. It has faced intense external political pressure from government, regulatory bodies, environmental groups, and road users to find more efficient, innovative ways to procure and provide customer-focused services. In the 1990s, the UK introduced radical changes in the procurement of public services, such as the Private Finance 

$1^{\text {st }}$ Order Concepts
$2^{\text {nd }}$ Order Concepts
Aggregate Dimensions

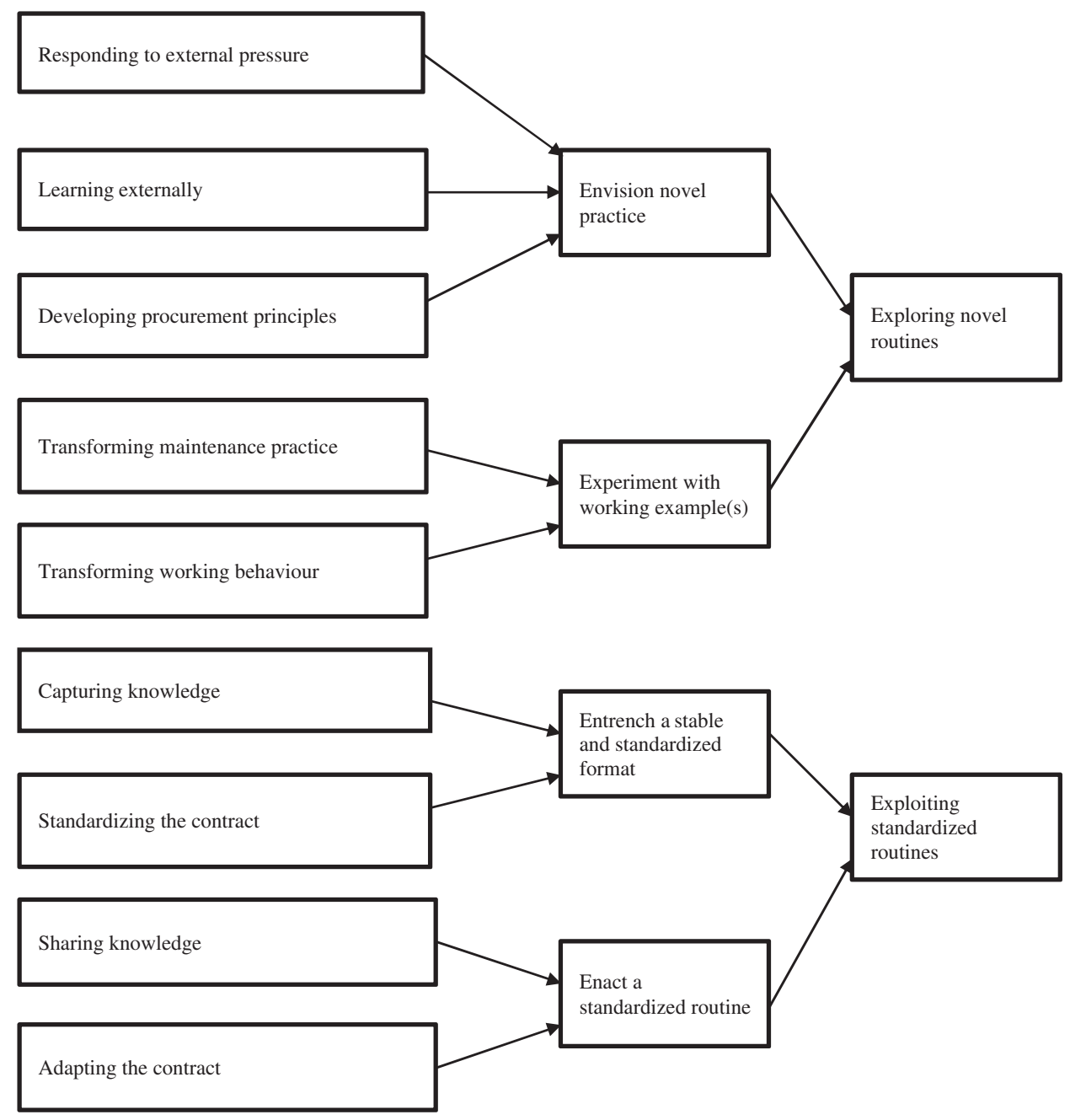

Fig. 1. Data structure.

Initiative in 1992 and Public-Private Partnership in 1997, encouraging public clients, including the newly founded HA, to transfer to the private sector responsibility for financing, designing, building, operating and maintaining public assets. Some of these new policies had already been implemented to improve the performance of other UK utility sectors, such as airports, energy, and water, when the HA was under pressure to adopt them. Several influential government-sponsored reports - such as the Latham (1994), Egan (1998), Transforming Government Procurement (2007) reviews (see Appendix A for relevant policy and industry documents) - emphasized the deficiencies of traditional forms of procurement and project delivery resulting in adversarial relationships characterized by conflict and distrust between government agencies and private contractors. Public sector clients, like the HA, were encouraged to develop stronger in-house client capabilities, forge collaborative relationships with contractors and introduce innovative new practices to improve performance.

In a political environment encouraging private-sector initiative and innovation, many senior HA managers were expected to explore new ideas and consider introducing novel forms procurement, risk-sharing contracts and collaborative partnering arrangements with suppliers to improve the performance of road maintenance. This included activities to maintain road safety and the more complex work needed to repair, replace and upgrade existing assets. Overall, at $£ 840$ million a year in
2010, maintenance was well over half of the HA's annual spending.

Our study examined how the HA, in response to the above pressures, created new maintenance routines based on two new types of contracts and attempted to deploy them consistently across the organization's geographical areas. This was a difficult challenge because, as a procurement manager in the HA explained, there is no direct one-to-one mapping between contracts (or artifacts) and routines:

“...contracts you can interpret without actually changing the letter of them, and that can translate through to quite a significant difference in approach out on the ground, but accepting, of course, you know, you only kind of, do that if it's actually, you know, fulfilling the outcome that you want. And necessarily, you know, these contracts... lend themselves to interpretation about, you know, how much you would do in terms of scope, rather than actually following the letter of the contract" (HA interview 2008).

Table 2 provides a summary of the key differences between types of maintenance contracts discussed below.

\subsection{MAC procurement}

In 2001, the HA introduced the Managing Agent Contract (MAC) for highways and trunk road maintenance services in response to 
Table 1

Representative quotations.

Concepts

Responding to external pressure $\quad$ "So therion

Responding to external pressure

\section{Envision}

"So there were two drivers [for the ideas for new procurement and contracts]. One was the Labour [Government] manifesto and then the other one was the Egan and Latham reports for innovation in the UK construction industry." (External consultant, 2008)

"There was a very, very significant push towards privatization of as many of these services that had been previously carried out by central and local government. There was also, I think, lobbying on the part of the private sector, particularly the contracting side, and to a lesser degree the design consultancy world, to say, well, you know, you should be letting us do this, we could do a better job. So there was lobbying, but I think also within the Department of Transport, and also within the Highways Agency there was a realization that the unevenness of practice needed to be addressed." (HA interview, 2010)

Learning from external sources

"Sorry, that's untrue to say we hadn't watched other people. We'd seen some of the stuff British Airport Authorities had done." (HA interview, 2008)

"Well, the OGC [Office of Government Commerce] provided useful examples as inspiration." (HA interview, 2009)

"Also, a lot of new people jointed the HA from various industries, public bodies as well as from the market. With their experience they brought in useful ideas." (HA interview, 2008)

Developing procurement principles

"Traditionally in government that's always been lowest price. . but clearly that was flawed, because it just drove down tender prices until they were unsustainable, and then you'd got all the contractual claims. So how could you develop? Our thought process was how do you develop a whole series of processes that will give, in effect, the chief executive, the chief accounting officer, the assurances that you are appointing the best suppliers to carry out the outsourced work, and at the same time it will be affordable, and you will improve budgeting certainty?. So that, that was a huge challenge" (HA interview, 2008)

"The envisioning from the HA was that InterRoute [prime contractors] was established as a new company, or a joint venture specifically aimed for serving the new HA market, for these new contracts whatever they turned out to be." (External contractor, 2008)

“. . have a clear vision, sort it out, and then drive it through the organization from the centre as you can't do it any other way." (HA interview, 2008)

\section{Experiment}

Transforming maintenance practice

'We are getting innovations within the EMAC contract. There is something new called the 'innovation bonus,' which, if they persuade the agency to change its written standards, they get, I think it's $30 \%$ share of the benefit once they've done a business case. I'm not aware yet that we've actually had a successful one of those. So in terms of innovation under the innovation bonus we're struggling, but there certainly have been innovations from things like increased recycling. And a lot of those innovations that don't qualify for an innovation bonus are probably driven by our monitoring, the KPI type monitoring basis. We have what are called area performance indicators that. . are identical across all the, what's now 12, I think." (HA interview, 2007)

"I think there are certain things within contracts you can interpret without actually changing the letter of them, and that can translate through to quite a significant difference in approach out on the ground, but accepting, of course, you know, you only kind of do that if it's actually. . fulfilling the outcome that you want." (HA interview, 2010)

"A total new mindset and procedure had to be put into place moving from the local authorities and the HA relationship to the new MAC contracts." (Consultant, 2009)

\section{Entrench}

Capturing knowledge

"I believe that the EMAC contract serves both as outcome of a learning process of improving the MAC contact internally in HA since the procurement unit collected HA experiences and transformed the contractual structure as well as an important test-bed facilitating learning processes, which can later be evaluated and its productive parts can be included in new contracts of both EMAC and MAC format. Also, the EMAC is facilitating local learning processes to occur more often due to the flexibility built into the contract in terms of the opportunity for contractor and client to stage minor pilot projects within the overall contract framework." (HA interview, 2007)

Standardizing the contract

"I think the ideas for standardization came from the experience on the MAC contract. So it was trying to roll out more of the early creation of the list of key principles we'd got. The early creation of the delivery team on a maintenance contract was seen to be as important." (HA interview, 2007)

"I'd much rather have a sort of mechanistic approach of actually drawing a benchmark, drawing out best practice, and then taking the whole lot forward as one, rather than, oh, I can change that contract, because that's a good idea, but I have to change 13 others in 13 other different ways. . I ought to be able to make a single change that will affect all 14." (HA interview, 2008)

Enact

Sharing knowledge

"So experience, the actual learning, was gained on the area level, so working with the contracts. .? the development of the contract then takes place at the more central level in the organization." (HA interview, 2007)

"Lessons learned from the MAC contract [are] captured within the HA through two bodies: TOCCA (traffic operations contract compliance audit) and PRIDE (performance review innovation and delivery)-the latter is more focused on improvement of contracts, not so much managing contracts. . Also, in 2003 there is a maintenance community set up across the HA areas to distribute best practices." (HA interview, 2007)

Adapting the contract

"So what you've got is a degree of uniformity but I think what the HA head of maintenance would argue is that in rolling the contract out you've got more than enough scope within the areas in which you can achieve, to tackle and have innovation without undermining the basis of the contract." (HA interview, 2008)

"You form a new contract and the agency staff who were managing the contract were suddenly faced, you know, they probably knew some of the concepts, but they'd had no involvement in developing the contract. They didn't know the thinking behind it. I try to make sure that the contract is going to deliver what we were looking for and that we understood." (HA interview, 2007)." 
Table 2

Types of maintenance contracts.

\begin{tabular}{|c|c|c|c|}
\hline Maintenance contract & $\begin{array}{l}\text { Managing Agent/Term Maintenance Contract } \\
\text { (MA/TMC) }\end{array}$ & Managing Agent Contract (MAC) & Enhanced Managing Agent Contract (EMAC) \\
\hline Contract structure & Contract with two organisations & Single-operator with one organisation & Contract with one organisation \\
\hline Reimbursement & Lump sum & Lump sum. Target costs & Target cost plus fee \\
\hline $\begin{array}{l}\text { Sustainability of scheme } \\
\text { size }\end{array}$ & $\begin{array}{l}\text { Thresholds are set to allow TMC to open up new } \\
\text { work areas but at a level to promote a smooth } \\
\text { workload }\end{array}$ & $\begin{array}{l}\text { The threshold values are generally } \\
\text { higher than those for the MA/TMC }\end{array}$ & $\begin{array}{l}\text { The provider carries out all routine service works } \\
\text { and renewal schemes of any value and } \\
\text { improvement work up to } £ 2 \text { million }\end{array}$ \\
\hline $\begin{array}{l}\text { Contractors' key roles and } \\
\text { responsibilities }\end{array}$ & $\begin{array}{l}\text { MA: Planning, programming, design supervision } \\
\text { and administration. TMC: Routine maintenance } \\
\text { and some capital works }\end{array}$ & $\begin{array}{l}\text { Act as contractor as well as supervisor } \\
\text { and management of design }\end{array}$ & $\begin{array}{l}\text { Client and the provider form a totally integrated } \\
\text { team that is motivated, responsible, incentivised } \\
\text { and empowered to achieve the aims of the client }\end{array}$ \\
\hline Programme budget control & $\begin{array}{l}\text { MA: Responsible for forward planning \& } \\
\text { supervision. TMC: Responsible for managing the } \\
\text { programme and budget within lump sum } \\
\text { activities }\end{array}$ & $\begin{array}{l}\text { Forward programming progresses } \\
\text { through value management process }\end{array}$ & $\begin{array}{l}\text { The provider assists the client in achieving its } \\
\text { objectives, including budget management }\end{array}$ \\
\hline $\begin{array}{l}\text { Incentives for improvement } \\
\text { and innovation }\end{array}$ & Long contract period allows for incentives & $\begin{array}{l}\text { Longer contracts allow greater } \\
\text { investment in staff. Focus on higher } \\
\text { level activities to promote innovation }\end{array}$ & $\begin{array}{l}\text { Efficiency share bonus. Innovation bonus. } \\
\text { Continuous Improvement bonus }\end{array}$ \\
\hline Risk management & $\begin{array}{l}\text { Shared risk register. Risk is managed and } \\
\text { minimised. }\end{array}$ & $\begin{array}{l}\text { Risk is spread between client and } \\
\text { provider. }\end{array}$ & $\begin{array}{l}\text { Risk is spread between client and provider. } \\
\text { Provider takes on more risk }\end{array}$ \\
\hline
\end{tabular}

government policy initiatives described above, which were encouraging the HA and other public clients to jettison to traditional procurement practices (e.g. fixed-price contracts which transferred risks to the supplier and promoted arms-length adversarial contractual relationships) and explore new principles of partnering and flexible risk-sharing contracts with incentives for innovation. The procurement contract specifically aimed at stimulating more collaborative behaviour in teams comprised of members from the client and contractor organizations.

MAC replaced the Managing Agent and Term Maintenance Contract (MA/TMC), which had been in place since 1996 and involved a complicated, overly elaborate and inefficient structure comprised of a client (the HA), MA and TMC. Under the MA/TMC approach, the HA managed the MA, the MA managed the TMC and the TMC performed routine maintenance and small capital projects. This arrangement was established following a period of downsizing because the HA had relatively little expertise in house and had to rely on an external body (MA) to specify and inspect the work undertaken contractor (TMC). In consequence, the HA had two contracts: one with the MA and the other with the TMC. The HA, as the client, retained ownership of the asset and contractor assumed responsibility for the risks incurred for the provision maintenance services.

MAC was an early attempt to embody some of the new principles identified in the HA 2001 procurement strategy (described in Table 3) in a new form of contract. Under MAC, the traditional MA and TMC roles were combined to form a single prime-contractor organization. As the project client, the HA now had one contract with a MAC organization. In many cases, consultant and contractor organizations responsible for MA and TMC under the old arrangement combined to form a new joint venture MAC organization. The contract was designed to create a simplified structure and stronger partnership between the client and MAC organization, thereby facilitating the innovation and improvements in efficiency. Most of the MAC contracts were awarded for a duration of 7 years ( 5 years plus a 2-year extension subject to effective performance). The long duration of the contract provided MAC organizations with the volume and predictability of work required to incur long-term investments in the skills and resources, carry out forward planning, and improve performance over time.

The MAC organization worked with the client (the HA) in an integrated project team which was formed before the design phase and continued during the execution of the contract. When mistakes or problems occurred during a project, the HA and MAC team were responsible for identifying them and working together to provide a solution.

The first MAC contract was awarded in Area 8 in Northamptonshire in September 2001 and implemented in 2002. This was an initial step in
Table 3

Ten Principles of delivery of Best Value (from 2001 HA procurement strategy).

1. Early creation of delivery team - early contractor involvement for more scope in innovation, better risk management, and forward planning of work programmes and resources.

2. Integrated and incentivised supply chain - early contractor involvement with its specialist knowledge, incentives for innovative ideas to give best value solutions.

3. Maintaining a competitive and sustainable supply chain - maintaining a good quality supplier base motivated and incentivised to work with the Agency.

4. Clear points of responsibility, no unnecessary layers of supervision clarifying roles and responsibilities to reduce contractual interface problems, eliminating resource wastage from unnecessary layers of supervision.

5. E-procurement - to make tender processes, communications and performance measurement more efficient.

6. Selection of suppliers on the basis of best value - identifying aspects of quality which add real, affordable value, using reality checks to confirm quality submissions and promises.

7. Fair allocation of risks - risks will be allocated to the party best able to manage them and the Agency will accept risks where suppliers are prepared to work in partnership to manage them and control the consequences.

8. High quality design - design solutions will be based on whole life value, assessed by reviews integrated with the Office of Government Commerce gateway review process. We are committed to achieving the principles of good design set out by the Government Strategy for Better Public Buildings.

9. Partnership approach based on long-term partnerships - moving from shortterm project partnering arrangements to long-term relationships for retention of skills and better resource and work programming.

10. Performance measurement with continual improvement targets establishing a five-year programme of improvement under the Clients' Charter scheme to confirm benefits in the form of cost and time-savings, reduced defects and accidents, and improved whole life value and satisfaction with the product.

a process eventually leading to the adoption of MAC contracts throughout the majority of England's strategic road network. However, the roll-out of the MAC contract was a long and drawn out process as many of MA/TMC organizations still had long-term contracts with the HA. Despite efforts to create uniformity and consistency across the maintenance programme, only 9 of the HA's 14 areas were using the new MAC contract as late as 2007 and the remaining areas continued to have contracts with MA/TMC organizations.

\subsection{EMAC procurement}

The new principles of partnering, innovation and risk sharing were extended even further in another area where the HA experimented with a new type of collaborative contract. Area 2 surrounding Bristol, was the only exception to the planned adoption of MAC procurement where an alternative approach called the Enhanced Managing Agent Contract 
(EMAC) was introduced in 2005. Influenced by the new strategic thinking about partnering, innovation and the HA's 'best value' strategy to achieve better outcomes for road users, a few of HA's senior procurement managers designed the EMAC to explore how incentives for innovation and collaborative principles could be embodied in a contract and tested in practice. Conceived as a radical alternative to MAC, the new contract adopted cost-reimbursable contracts, in contrast to the lump-sum fixed price still used for MAC (see Table 2). The EMAC organization was selected based on the quality of the proposed solution, rather than a lowest-cost bid. EMAC continued to include some of the core principles underpinning the MAC contract including an integrated team project, co-location and single contract with the client. However, EMAC focused attention on the quality of services provided and was designed to achieve desired outcomes, rather than detailed technical specifications on time and within budget.

Under EMAC, the contractor did not simply carry out work under the direction of the client. It was now responsible for helping the client address strategic issues, allocate budgets and manage risks. For example, as one of HA's manager explained:

"There's a lot more management responsibility...I mean, with, with the MAC it's basically self-managing and, and it just reports back. With the EMAC there's a lot more administrative role for the Agency and a lot more management heads up project management role,... that's something else, we have to develop the skills and the contract management skills within the Agency itself."

With much less emphasis on planning work in detail years in advance, EMAC offered a more flexible means of undertaking work when and where it was needed and responding rapidly to unforeseen changes in demand for maintenance services. EMAC was run on an open-book basis so that the HA had full access to contractor's detailed costs and forecasts by route, activity, budget and resources. To the surprise of the managers involved, the first, and only, EMAC contract was awarded in 2005.

\section{Findings}

\subsection{The four-step process of routine development}

Our analysis of how the HA created and implemented new ways of performing road maintenance led us to identify a four-step process of new routine development involving phases of envisioning, experimenting, entrenching and enacting (illustrated in Fig. 2).

\subsubsection{Envisioning}

In the first phase of the process, the HA faced external pressures to achieve government policy objectives by improving the performance of road maintenance services. The HA's the central procurement department was responsible for finding a way of achieving those objectives. Managers faced the difficult challenge of taking rather generic policy statements about collaboration, risk sharing and partnering and turning them into concrete processes that could be reliably and consistently performed by operational units in the geographical areas. They began by envisioning the outcome they wanted to achieve: an approach to road maintenance based on a collaborative client and contractor relationship implemented consistently across the HA's geographical areas. This process of envisioning captured the activities undertaken by HA's procurement managers over period of several years when they identified and defined the new principles described in Table 3.

In its efforts to create a new approach, the HA decided to "take a more strategic view on delivering maintenance projects, acknowledging that it takes leadership and that the HA needs to bring in and develop skills" (HA interview 2008). The procurement department drew on government reports, consultancy studies, and knowledge of successful procurement practices found in other utility and infrastructural industries. Consultants with knowledge and experience in other industries and leading-edge clients (e.g. British Airports Authority) were recruited to lead the procurement team. As an HA director explained:

"We recruited some of the new people for procurement from outside. They were either working in the supply chain, supporting the supply chain, or in other industries where commercial issues were similar" (HA interview 2008).

As they refined the principles described in Table 3, the strategic unit translated these ideas into two alternative contracts (MAC and EMAC), which were seen as the main tools to implement the principles consistently across areas. As one manager commented, HA's procurement team:

"were very much driven by policy. They had driven MAC, changed MAC and then EMAC came about in the Labour Party [which subsequently won the UK government election] manifesto" (HA interview 2008).

The HA's procurement department had previously developed various trances of MA/TMC contracts and used the knowledge and experience gained to identify what elements of existing practices could be combined with the new collaborative principles for undertaking road maintenance. Three of the HA's senior managers in the procurement unit were responsible for drafting the MAC contract and processes that could achieve the HA's overall corporate strategy and new objectives for collaborative procurement. In an offline cognitive process, these managers explored alternative solutions and selected the preferred combination of existing and new elements which were codified in a new

\begin{tabular}{|c|c|}
\hline STEP 1: ENVISION & STEP 2: EXPERIMENT \\
\hline $\begin{array}{l}\text { Strategic units develop } \\
\text { new principles to } \\
\text { achieve desire outcome }\end{array}$ & $\begin{array}{l}\text { Selected operational } \\
\text { units develop working } \\
\text { examples of new } \\
\text { routines }\end{array}$ \\
\hline $\begin{array}{l}\text { - Explore alternatives } \\
\text { - Search inside and } \\
\text { outside the organization } \\
\text { - Development of } \\
\text { anchors (contracts) for } \\
\text { the routines }\end{array}$ & $\begin{array}{l}\text { - Explore how to adapt } \\
\text { routines and create new } \\
\text { patterns of action } \\
\text { - Trials of new routines } \\
\text { around the anchors } \\
\text { (contracts) }\end{array}$ \\
\hline - Off-line thinking & - On-line practice \\
\hline
\end{tabular}

Exploration

STEP 3: ENTRENCH
Strategic units select
routine and stabilize
standardized format for
replication
- Evaluate trials
- Define the anchors for
the routines
- Prepare for replication
across multiple sites
- Develop knowledge
sharing mechanisms
- Off-line thinking

STEP 4: ENACT

Multiple operational units implement new routine across sites

- Exploit opportunities to increase performance and reliability

- Adjust routines to

local conditions

- Share knowledge and

experience

- On-line practice

Fig. 2. The four-step process of new routine creation and replication. 
type of contract. While the MAC contract was being implemented in selected trials, the procurement team decided to develop EMAC as a radically new type of contract incorporating the latest thinking about risk-sharing collaboration and innovation which could substitute for MAC in the HA's next generation of contracts.

By 2005, the HA had, therefore, developed two alternatives ways of undertaking collaborative procurement: MAC and EMAC. Although there are distinct differences in the principles underpinning the two contracts, both were designed to stimulate collaboration and innovation, while avoiding the waste and inefficiencies of the past, such as having "professionals checking the work of other professionals" (HA interview 2007). As one of the HA's procurement managers explained:

“...what we've done with EMAC is, you know, we're trying to get them [sub-contractors] to act on our behalf rather than incentivize them to work on their own behalf. So we've tried to remove a lot of barriers that were between them and us" (HA interview 2008).

The operational units (the HA regional areas) were not consulted during the envisioning step because the procurement team felt that the experience gained by working on the HA's existing contracts and associated path dependencies might constrain creative efforts to explore new ways of delivering road maintenance.

\subsubsection{Experimenting}

The experimenting phase began when operational units in the HA's geographical areas were selected as pilot trials to explore how to implement the new MAC and EMAC contracts. The teams in the trials were given the task of turning the new contracts and processes for road maintenance into day-to-day maintenance activities. In an online experiential process of trial-and-error learning, members of trial teams had to adapt behaviours acquired to perform existing routines based on previous contracts and discover the new ways of working collaboratively stipulated by the MAC and EMAC contracts. The HA's procurement department assumed that the members of the trial teams "knew what they needed to know" and were "left to their own devices" to execute the new contracts (HA interview 2008). The teams received the contracts and process documents and were expected to discover what new behaviours and sequence of activities would be required to perform the roles broadly described in the contracts, achieve specified performance targets, identify corrective actions to address sub-optimal performance, and establish effective lines of communication between the client and contractor.

The HA launched four new MAC contracts in 2002 (including Area 9 where we conducted our interviews) when the previous tranche of MA/ TMC contracts were coming to an end. When members of the integrated client and contractor team in Area 9 team first read the MAC contract and process documents, they had little or no idea how to put them into practice and received almost no further guidance from the HA's procurement team. Contrary to the procurement department's expectations, the Area 9 team had only a "very sketchy" knowledge of how to proceed and "a lot of things were worked out on the hoof" (HA interview 2008). Apart from one or two procurement staff in Area 9, few people had a thorough understanding of the MAC contract. The HA's central procurement department responsible for developing the MAC contract literally "disappeared when the contract was awarded" (HA interview). Over a period of about two years, the team had to work out how to implement the contract by "talking amongst ourselves" (HA interview 2008), adapting previous routines and developing the knowledge needed to achieve more predictable and reliable performance. As an HA manager explained, "Success doesn't come automatically; you have to keep on testing" (HA manager interview 2007). Not surprisingly, it took a considerable amount of time before the new contracts and processes could be turned into a reliable operational routine.

The HA's staff working in Area 9 had previously developed the routines required to work with the traditional MA/TMC contract based on an arms-length and often adversarial relationships. When asked to work with the new MAC contract, many staff found it difficult to collaborate with the contractor in an integrated project team. They continued "operating the old-fashioned way for the next 12-18 months. Then there was a slow sea change" (HA interview). With little help from the HA's procurement department, members of the client and contractor team in Area 9 spent a lot of time and effort promoting a culture of partnering during the first six months of the MAC contract by holding workshops and mentoring staff. These efforts were successful because when the MAC contract was initially introduced:

"You could almost walk into a room and see who was [the contractor under the old procurement] and who was [the consultant (MA) under the old procurement]. Within a year, you couldn't" (HA interview 2008).

By 2008, after several years of working with the new contract, members of the Area 9 team had established the routines required to work in a collaborative and risk-sharing arrangement. Achieving such reliable and predictable performance was, however, a protracted and painful process of trial-and-error learning for members of the Area 9 team who felt that the HA's procurement department "should have helped us with a lot more training" (HA interview 2007).

Introduced in 2005, three years after the first MAC contract, EMAC was a cost-reimbursable contract designed to explore how maintenance services could be provided when the client-contractor relationship involved a high degree of cooperation and risk sharing. Under EMAC, the contractor received a share of the profits depending on its performance. The first and only EMAC contract was introducted in Area 2 around Bristol and awarded to a consortium called InterRoute. Area 2 was selected partly because its previous MA/TMC contract arrangement had recently been completed, providing a convenient opportunity for the HA to pilot the EMAC. But it was also chosen because members of the Area 2 had the capabilities and knowledge required to engage with and test the EMAC approach. But learning how to implement EMAC took much longer than the MAC contract. Area 2 faced the additional challenge of moving directly from a traditional MA/TMC structure to an EMAC contract. They could have benefited from the cumulative buildup in experience and knowledge gained by first learning about MAC and then using that experience to move incrementally towards EMAC. As one manager in Area 2 explained: “...forget the EMAC, just getting it together as a MAC takes a year, 18 months or so" (HA interview 2008).

Although the Area 2 had shown that EMAC offered improvements in performance and were confident in their belief that the HA should select this contract for large-scale implementation, it was eventually abandoned when the MAC contract was selected as the HA's preferred approach highways and road maintenance.

\subsubsection{Entrenching}

The entrenching phase began when responsibility for routine development passed back to the HA's central procurement department. We use the word 'entrench' to describe the offline work undertaken to select, define and prepare of the new standardized maintenance contract for large-scale replication across the HA's operating units. The HA's decision in 2004 to use MAC as the preferred contract for the next generation of maintenance activities was confirmed when 9 MAC agreements were awarded and the original five-year MAC contracts were given two-year extensions. Yet the HA's procurement team still wanted to consider whether EMAC implemented in Area 2 in 2005 might offer a viable replacement for the next generation of MAC contracts. EMAC was, however, always considered a risky option because it introduced radically new and unproven principles which had not been applied to road maintenance, such as a cost-plus contract and more strategic risk-sharing partnership between the HA and the contractor.

The HA's procurement managers wanted to see how EMAC worked in practice to identify whether it could be substitute for MAC. Audit and reviews were conducted to evaluate the MAC and EMAC pilot projects. 
The intention was to use the information gathered to reach an informed decision about which contract to select and prepare for large-scale implementation. As one manager put it, "there was a desire from the top to have greater consistency and uniformity in terms of these contracts" (HA interview 2008). Audit teams visited the pilot Areas for a few days and identified how local units modified their bevahiours and activities to improve the performance of the contracts. In-house and external consultants were employed to identify compliance failure, take remedial measures, and drive process improvements. The audits helped the procurement team understand what parts of the contracts worked well and how they could be improved. Beyond working on the contracts, the HA strategic unit sent 'Focus on Best Practice' report sheets to each Area MAC team, inviting them to provide examples of best practice that could be disseminated across the MAC areas.

Under pressure to implement the government's new agenda to improve the performance of public infrastructure services as quickly as possible, the HA's procurement team did not wait to fully evaluate the performance of each contract before launching new trials. Commenting on why the MAC contract was implemented in 2002 in three other areas before waiting for feedback from Area 8 to decide how this maintenance approach could be improved, one manager said:

“...rather than wait for lessons learnt. The HA went straight ahead with commissioning and inviting tenders for the next three MACs in the Midlands Areas 7, 9 and 11. We went ahead with those before any lessons were learnt from Area 8" (HA interview 2008).

In the words of one senior manager, there was a feeling that the HA was "addicted to change" (HA interview 2008). As a manager in Area 9 pointed out:

"One of the problems the HA have got is that they constantly go from this to these different models, without assessing the real benefits of that first model and without briefing out the requirements of the second one" (HA interview 2008).

The same point was reiterated by another manager:

“...First you think we've got EMACs and then we're not doing EMACs anymore, we're doing something else" (HA interview 2008).

Our interviews suggest that the need to demonstrate "quick wins" (HA interview, 2008) contributed to the HA's decision to abandon the EMAC contract. Asked explicitly why EMAC was not selected, a senior manager emphasized that the HA had to demonstrate its ability to respond to urgent political pressures. There was a belief that the HA could not afford to delay the decision while waiting to hear about the the relative advantages of each contract for enhancing the effectiveness of the HA's maintenance activities:

"I think that there was a time imperative, in so far as many of the local governments were changing anyway, and many of those were actually moving to outsourcing...because of their own financial pressures and also pressure from central government on, you know, funding them in the form of grants" (HA interview 2008).

The HA Manager went on to explain:

"There was also, you know, the overarching political pressure to privatize as much as possible, and really the pressure was then on to actually roll out the MAC form as quickly as it could possibly be done. But to be frank, the EMAC was seen as a little bit of an entertaining nicety. But it really wasn't sufficient to say well, we'll go not go ahead with the wider programme....I think we weren't sufficiently confident in the EMAC contract as we go forward, and indeed the decision has now been made that there won't be another EMAC contract" (HA interview 2008).

The HA's decision to continue with MAC rather than a new generation of EMAC contracts was taken before the procurement team had time to evaluate this alternative approach. According to one HA manager of Area 2, "everybody feels it's [EMAC] doing well" (HA interview 2008). Yet most of the managers we interviewed always believed that only one of the proposed trial contracts - the MAC - would be selected for widespread implementation across the HA's geographical Areas. Although the procurement office recognized that EMAC was a more flexible and responsive form of contract, they believed that more knowledge and experience had be acquired to improve the contract before it could be selected as HA's preferred approach for nationwide road maintenance. For example, some of the Area 2 managers believed that an element of fixed price tendering could be brought back into the EMAC contract, but recognized that reintroducing a lumpsum contract would undermine the EMAC approach (HA interview 2008). The decision to jettison EMAC was controversial, with other interviewees arguing that the failure to wait and accommodate the learning gained from the performance of the EMAC pilot reflected the preconceived notions of individuals in HA's procurement department about the advantages of the MAC contract.

\subsubsection{Enacting}

The enacting phase began when the revised MAC contract was implemented across the HA's geographical areas. Although the HA attempted to implement the MAC contract in a consistent and standardized way, there was a recognition that each contract had to be adjusted to the context of each local area, which varied considerably in terms of the configuration of routes, density and type of traffic and physical geography. As one manager: "we're not even doing things in the same way within a given area" (HA interview 2008). Further trialand-error learning and experience had to be acquired by the operational units to ensure that the routines were adjusted to fit the local requirements and challenges of each geographical area.

The HA operational units involved in this final step of experiential online learning continued to adapt their routines during the widespread roll out of the new contract. Each unit benefited from learning acquired through HA's central procurement department and from the other adjacent operational areas running MAC contracts. The HA ensured that lessons learnt from the initial round of trial MAC contracts were used incrementally to improve subsequent tranches of contracts during the rollout. For example, the procurement department provided the Area 1 MAC team in Exeter with training and advice on what to expect during the implementation of the new contract. An Area 9 manager also visited the Area 1 MAC to provide cross-learning from one MAC to another. The operational units assisted in efforts to achieve some uniformity in routines by establishing a 'Maintenance Community and Maintenance Best Practice Group', including staff from the contractor companies across the HA maintenance areas, to share their knowledge and experience with the new MAC contracts.

\section{Discussion}

Our research findings show how new routines develop as an integrated process in four distinct steps: envisioning, experimenting, entrenching and enacting. We contribute to the literature on organizational routines by identifying how different organizational levels and capabilities shape the development of new routines and how distinct cycles of variation and selective retention occur during in each step of the process.

\subsection{Organizational levels and capabilities}

To ground our discussion, Fig. 3 illustrates how the steps in our process model are undertaken by two different levels of organization (strategic and operational) and correspond to the phases (exploration and exploitation) identified in capabilities research. While managers in strategic and operational units were present throughout the creation and replication of the new routine, one or other unit prevailed during each step in the process. The strategic unit was primarily concerned 


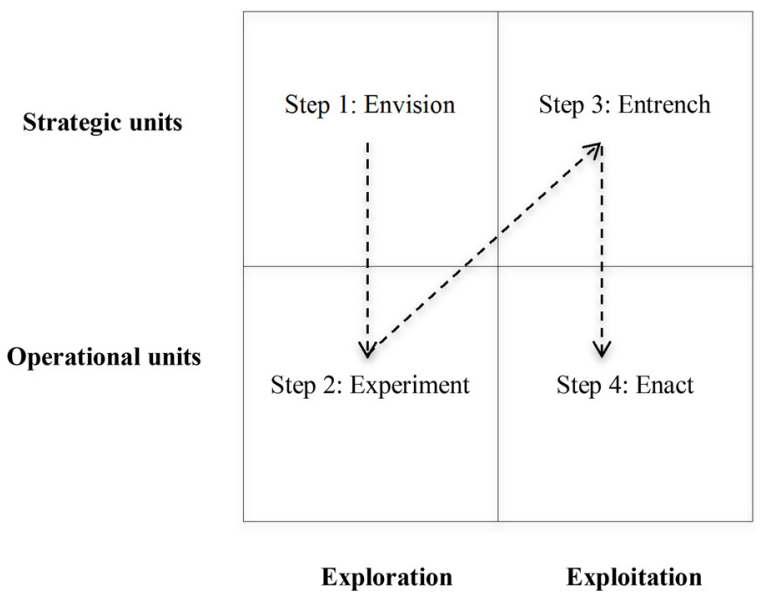

Fig. 3. Routine creation and replication process: the long and winding road.

with envisioning and entrenching, whereas the operational units were involved in experimenting and enacting the new operating routines.

The dual-routines approach in capabilities research identifies the higher and lower-order levels of the organization responsible for creating and replicating new routines across multiple sites. Strategic units - the HA's strategy and procurement departments - employed dynamic capabilities to search for alternatives to the prevailing operating routines, select the new routine, and prepare for large-scale replication. Managers in the strategic units played the role of 'routine developers' by envisioning a desired end state and taking the action required to achieve it. They created the artifacts around which the new routines were developed (a new type of contract and associated processes) and selected the preferred template to support the consistent and uniform roll-out of new routines across multiple sites.

Operational units - in the HA's regional areas - were responsible for exploring how to develop entirely new routines associated with the contract they employed (the MAC and EMAC contracts and procedures) and making the adjustments required during the large-scale replication of the preferred routine (the MAC contract). Staff in the operational units were 'routine performers'. They had to abandon their existing routines, change their behaviour and create the new patterns of action required to establish new routines in pilot trials. In the process of largescale replication, actors across multiple sites learned from each other as they made the additional adjustments needed to support the adoption of the new standardized practice.

In contrast with traditional view that dynamic capabilities are applied in a top-down, unidirectional way to create or replicate new routines (Zollo and Winter, 2002; Helfat and Winter, 2011), our findings - in line with the observations in recent research (Jonsson and Foss, 2011; D'Adderio, 2014) - suggest a more interactive and recursive relationship between higher and lower-order activities. As our four-step process model illustrates, dynamic capabilities are employed to modify or develop new routines and select among alternatives based on the feedback and learning gained from trial experiments with lower-order operational routines.

A stream of research points to the development of routines being shaped by the coexistence of cognitive and behavioural logics (Gavetti and Levinthal, 2000; Gavetti, 2005; Eggers and Kaplan, 2013). Our findings are consistent with research showing how routines may be interpreted and performed in different ways by actors at different levels of the organizational hierarchy and follow alternative trajectories of action (Obstfeld, 2012; D'Adderio, 2014). As illustrated in Table 4, managers in the higher-level strategic units were guided by a cognitive logic of forward-looking, creative and deliberate choices, whereas staff in the lower-level operational units followed a behavioural pattern of backward-looking, experiential and emergent action.

The existence of opposing cognitive and behavioural rationalities may contribute to breakdowns in communication, conflicts and tensions between organizational levels (Salvato and Rerup, 2011). The strategic units in our study, for example, failed to provide operating units with the support they need to modify and create the new routines required to implement the trial MAC and EMAC contracts. The primary objective of the pilot trials was to take the time required to explore how the new artifacts and principles would introduced in actual practice, whereas managers in the strategic units were motivated by the need to exploit what had been learned and move as quickly as possible to the next step. Guided by different logics, pressures and time constraints, actors working at these different levels often neglected to exchange knowledge or failed to learn from each other during each step in the process.

Although our observations about the relationship between higher and lower-order capabilities and tensions between logics are largely consistent with prior research, we now advance the debate in capabilities research by showing how evolutionary processes of variation and selective retention are performed by actors working different levels of the organizational hierarchy.

\subsection{Evolutionary processes and phases}

Building a clearer view of the larger scale dynamics of new routines requires an understanding of how evolutionary processes of variation and selective retention occur in practice. Zollo and Winter (2002) argue that variation and internal selection correspond to a broader phase of exploration, while replication and retention to a subsequent phase of exploitation. Our findings suggest that there is no simple one-to-one correspondence between the stages of evolution depicted in Zollo and Winter's (2002) model and the actual practice of routine creation and replication. Our model (Fig. 3) identifies how each step in a process performed by actors working at different organizational levels contains distinctive mechanisms of variation and selective retention.

The exploration phase in our model involved two cycles of variation and selective retention. The envisioning step was a deliberate, off-line activity undertaken to generate and select alternative routines

Table 4

Contrasting cognitive and behavioural logics.

\begin{tabular}{|c|c|c|}
\hline & Strategic units & Operational units \\
\hline \multirow[t]{2}{*}{ Approach } & - Teleological vision & - Evolutionary adaptation \\
\hline & $\begin{array}{l}\text { - Achieve standard results across local areas } \\
\text { - Achieve demonstrable results quickly }\end{array}$ & - Stabilize routines within the contract \\
\hline \multirow[t]{2}{*}{ Logics } & - Offline, cognitive & - Online, experiential \\
\hline & $\begin{array}{l}\text { - From vicarious experience (other industries, operational units) } \\
\text { - Movement of personnel } \\
\text { - About the contract }\end{array}$ & $\begin{array}{l}\text { - From direct experience through experimentation } \\
\text { - Maintenance communities and stable teams } \\
\text { - About the routines }\end{array}$ \\
\hline Mindset & - Radical change, but the operation level "knows how to do it" & $\begin{array}{l}\text { Experience helps fill gaps in knowledge and } \\
\text { guides interpretation of the contract }\end{array}$ \\
\hline
\end{tabular}


developed to achieve improvements in organizational performance. Because our research focused on the creation of new routines, these alternatives were based on novel principles (Baden-Fuller and Winter, 2005) rather than existing templates (Winter and Szulanski, 2001). Members in the strategic units developed novel ideas and principles, and simultaneously evaluated alternatives before settling on two approaches. These 'routines as rules' were codified and embodied in two artifacts, the MAC and EMAC contracts and their attendant process documentation.

In the experimenting step, the two contracts were transferred and converted from 'routines as rules' (the two artifacts) to 'routines as patterns of action' by members of the pilot trials in the operational units. The stable properties of rules contain elements that guided, but did not determine behaviour. Actors adapted to the rules and selected elements among new patterns of action. The artifacts were tested online in a trial-and-error learning process and new patterns of action were generated and selectively retained in the new routines (Pentland et al., 2012; Levinthal and Marino, 2015). Variation within a broad pattern of action was generated when the actors changed their behaviours, abandoned existing routines and found new ways of working associated with the contracts and process documentation. Selection occurred when specific variations within those patterns were repeatedly tried out and those behaviours that worked well were retained by staff in the operational trials. When this second cycle was completed, the artifact and newly selected routine moved to the next phase.

The exploitation phase in our model also involved two cycles of variation and selective retention. In the entrenching step, the learning gained during the operational trials provided managers in the strategic units with the knowledge they required to select one of the two new trial routines as a working example that could be prepared for widespread replication. Audits and site visits were undertaken to evaluate the performance of the MAC and EMAC contracts and identify which patterns of action and practices could be codified and replicated. In an offline process, managers in the strategic units selected the MAC contract as the preferred template for large-scale implementation. A revised version of the MAC contract and a new guidebook provided a detailed description of the processes that the operational teams could use to support the consistent and uniform application the new maintenance routine across the local operating units.

In the enacting step, responsibility for the routine passed back to the operational units. The selected routine was refined and developed when it was adapted to the local requirements of each operating unit. A more constrained cycle of variation and selective retention occurred within the wider community of operational units as they enacted the routines, shared practices and adapted to local conditions.

By studying the larger pattern of new routine development over an extended period of time, our findings show that distinct cycles of variation and selective retention occur throughout the process and involve a series of interactions between strategic and operational units. Variation is not reducible to an initial exploratory stage in the creation of new routines when senior managers in strategic units engage in a purely off-line cognitive process to discuss alternatives and select the most appropriate one for implementation across sites. A distinct cycle of variation and selective retention occurs, for example, prior to largescale replication when actors in trial operational units experiment with the new approaches and develop local versions of a routine.

We contribute to research on variation and selective retention by empirically showing how broad types of routines (the patterns of action associated with EMAC and MAC contracts) are selected and locally adapted. Recent search suggests that variation and selection depends on actions at two different levels (Levinthal and Marino, 2015). The first level refers to the choices between different classes of routines and second level refers to local adaptation (or 'plasticity') within each class of routine. Our research shows that these two levels are performed by actors in strategic and operational units. Actors working at the strategic level selected different classes of routines (MAC and EMAC) for the operational trials. Actors working on each class of routine in the operational trials engaged in a localized process of variation and selective retention when they adapted their behaviours, generated new patterns of action, and shared experiences with other units. Successful variations were then selected by the strategic units, refined and incorporated in updated versions of the contract, and prepared for large-scale replication across many operational units in the organization.

\subsection{Future research}

We adopted a capabilities perspective because we wanted to understand how new routines are created and replicated to achieve an organization's strategic objective to improve performance. Whilst capabilities research studies larger patterns of development, including the organizational structures and evolutionary processes shaping routine dynamics, it neglects to provide a close observation of how actors perform routines in a specific time and place. Our findings identify two areas where future research may build bridges between the previously separate capabilities and practice approaches to the study of organizational routines (Parmigiani and Howard-Grenville, 2011; HowardGrenville et al., 2016)

First, in line with recent calls for multilevel studies of routines (Salvato and Rerup 2011), future research might use a capabilities lens to 'zoom out' and study the organizational structures and processes within which new routines evolve and a practice lens to 'zoom in' and provide a finer-grained analysis of the interpretations and behaviours of individual actors performing routines during each step in the process (Nicolini, 2009; Howard-Grenville et al., 2016). Capabilities research emphasizes that organizations undertake a variety of practices at a strategic level and deploy dynamic capabilities to modify, reconfigure and build new routines to achieve strategic goals. Conceived as an exogenous process of change, managers envision a desired end state and engage in deliberate process of variation and selection to develop and retain a new and improved routine. This perspective identifies how managerial interventions modify and create new lower-order routines in the operational units, but pays less attention to the actual practices of variation, selection and retention occurring endogenously when the new routines are performed by individual agents.

Second, a capabilities perspective may be enriched by understanding how artifacts - including written documents, procedures and templates - shape and provide the context within which new routines develop. The concept of a template in capabilities research may be treated as a set of artifacts in the form of detailed documentation that guides the behaviour and actions of those responsible for replicating the routine. In early studies of replication, templates played a one-sided role in the replication process by enforcing standardization and providing a stable basis for improvement once the transfer had been accomplished (Winter et al., 2012). More recent research recognizes that because these stable properties generally fail to furnish a complete formulization, the set of practices and actions associated with a template have to be developed through a process of local adaptation (Jensen and Szulanski, 2007; Jonsson and Foss, 2011; D'Adderio, 2014).

The idea that artifacts shape but do not determine behaviour and patterns of action is developed much further in practice research which shows that artifacts may influence emergent patterns of action and provide the structure that hold routines together (D'Adderio, 2011). In our research, the contract was used by the strategic units to articulate the procedures required to guide the performance of new road maintenance routines, whereas the operational units had to work out how to turn codified knowledge into functioning routines based on tacit knowledge and learned experience. The two alternative contracts provided a detailed description of the roles and responsibilities of parties, and performance criteria, but did not specify precisely how the processes could be enacted in practice. In this way, artifacts may help to balance stability and variation (Turner and Rindova, 2012), and 
efficiency and flexibility in routines (Cohendet and Simon, 2016).

In our study, artifacts helped the operational units "orient to absences" (Jarzabkowski et al., 2012) by focusing their attention on what was missing and had to be addressed when developing the new routines. Only after working examples of the new routines had been developed in operational trials, could actors in the strategic units select and prepare a standardized representation of the new routine (the contract and written procedures) for large-scale replication. While prior studies have shown how artifacts enable stability and change (Turner and Rindova, 2012; D'Adderio, 2014) and support ecologies of routines (Seele and Grand, 2016; Spee et al., 2016), future research could explore how artifacts provide anchors or fixed points around which new patterns of action and routines emerge and stabilize over time (Birnholtz et al., 2007) and adapt to the local needs (Jonsson and Foss, 2011).

\section{Conclusions}

Drawing upon various strands of capabilities research, this paper showed how new routines are created and replicated across multiple sites within organizations. We argued that the development of a new routine can be conceptualized as process involving four steps - 'the long and winding road' - in a life cycle from initial creation to large-scale replication. As we showed, evolutionary processes of variation and selection occur during each step in a process led by alternating actors in strategic and operational units. We suggested that our conceptualization of routine creation and replication offers a way of integrating capabilities and practice perspectives through multilevel research. Capabilities research shows how routines are created and performed by organizations in a search to achieve improvements in performance, whereas practice research provides a more thorough analysis of the behaviours and interpretations of people actually performing routines. We believe that by specifying the managerial actions undertaken by strategic and operational units, our research provides guidance for organizations and individuals seeking to navigate the difficult and challenging process of creating and replicating new routines across multiple sites.

\section{Acknowledgements}

We acknowledge the time and insights of professionals at the Highways Agency in England and contracting organizations who participated in this research. The paper benefited from comments and advice offered by Erkko Autio, Charles Baden-Fuller, Julia Balogun, Markus Becker, Simone Ferriani, Gerry George, Royston Greenwood, Nicolai Foss, Ray Levitt, Sam MacAulay, Stephan Manning, Marie Louise Mors, Paul Nightingale, Niels Noorderhaven, Nelson Phillips, Andrea Prencipe, Mari Sako, Ammon Salter, Richard Scott, Jonas Söderlund, Frederik Tell, and Finn Valentin. We thank seminar and conference participants at Academy of Management 2010, DRUID Conference 2009 and 2010, Advanced Institute of Management (AIM) workshop 2010, Cass Business School, Linköping University, SMG Copenhagen Business School, Norwegian Business School, Stanford University and KTO-GREDEG-OFCE. Finally, we thank the anonymous reviewers and our editor Ben Martin, who helped us sharpen and strengthen the paper's contribution.

\section{Appendix A. Secondary Source Documents}

Contract Journal (2004). MACs to be extended, 8 September, 2004.

Contract Journal (2005). Amey and Mouchel to split roads partnership, 22 June, 2005.

Egan, J., 1998. Rethinking Construction, Construction Task Force Report for Department of the Environment, Transport and the Regions.
HMSO, London.

Highways Agency (2000). Making maintenance the priority: Highways Agency Strategic Plan for Maintenance, Department of Transport.

Highways Agency (2001). Delivering best value solutions and services: Highways Agency Procurement Strategy, Department of Transport.

Highways Agency (2005). Procurement Strategy Review 2005: Delivering Best Value Solutions and Services to Customers, Department of Transport.

Highways Agency (2005). Customers First: the Highways Agency Corporate Plan. Department of Transport.

Highways Agency (2007). Helping you with your journey: 07-08 Highways Agency Business Plan, Department of Transport.

HM Treasury (2007). Transforming government procurement. January 2007.

Latham, S.M., 1994. Constructing the team. HM Stationery Office London.

\section{References}

Ansari, S., Reinecke, J., Spaan, A., 2014. How are practices made to vary? Managing practice adaptation in a multinational corporation. Organ. Stud. 35, 1313-1341.

Baden-Fuller, C., Winter, S.G., 2005. Replicating organizational knowledge: principles or templates? Available at SSRN 1118013.

Barley, S.R., Kunda, G., 2001. Bringing work back in. Organ. Sci. 12, 76-95.

Becker, M.C., 2004. Organizational routines: a review of the literature. Ind. Corp. Change 13, 643-678.

Birnholtz, J.P., Cohen, M.D., Hoch, S.V., 2007. Organizational character: on the regeneration of camp poplar grove. Organ. Sci. 18, 315-332.

Cacciatori, E., 2012. Resolving conflict in problem-solving: systems of artifacts in the development of new routines. J. Manage. Stud. 49, 1559-1585.

Charmaz, K., 2014. Constructing Grounded Theory. Sage.

Cohen, M.D., Bacdayan, P., 1994. Organizational routines are stored as procedural memory: evidence from laboratory study. Organ. Sci. 5 (4), 554-568.

Cohendet, P.S., Simon, L.O., 2016. Always playable: recombining routines for creative efficiency at Ubisoft Montreal's video game studio. Organ. Sci. 27 (3), 614-632.

Corley, K.G., Gioia, D.A., 2004. Identity ambiguity and change in the wake of a corporate spin-off. Adm. Sci. Q. 49, 173-208.

Cyert, R.M., March, J.C., 1963. A Behavioral Theory of the Firm. Prentice-Hall, Enlewood Cliffs, NJ.

D'Adderio, L., 2011. Artifacts at the centre of routines: performing the material turn in routines theory. J. Inst. Econ. 7 (2), 197-230.

D'Adderio, L., 2014. The replication dilemma unravelled: how organizations enact multiple goals in routine transfer. Organ. Sci. 25 (5), 1325-1350.

Daneels, E., 2008. Organizational antecedents of second-order competences. Strateg. Manage. J. 29, 519-543.

Daneels, E., 2010. Trying to become a different type of company: dynamic capability at Smith Corona. Strateg. Manage. J. 32, 1-31.

Di Stefano, G., Peteraf, M., Verona, G., 2014. The organizational drivetrain: a road to integration of dynamic capabilities research. Acad. Manage. Persp. 28 (2), 307-327.

Dionysiou, D.D., Tsoukas, H., 2013. Understanding the (re)creation of routines from within: a symbolic interactionist perspective. Acad. Manage. Rev. 38, 181-205.

Dittrich, K., Seidl, D., 2018. Emerging intentionality in routine dynamics: a pragmatist view. Acad. Manage. J. 61 (1), 111-138.

Easterby-Smith, M., Lyles, M.A., Peteraf, M.A., 2009. Dynamic capabilities: current de bates and future directions. Br. J. Manage. 20 (1), 1-8.

Eggers, J.P., Kaplan, S., 2013. Cognition and capabilities: a multi-leve perspective. Acad. Manage. Ann. 7 (1), 295-340.

Ethiraj, S.K., Kale, P., Krishnan, M.S., Singh, J.V., 2005. Where do capabilities come from and how do they matter? A study in the software services industry. Strateg. Manage. J. 26, 25-45.

Feldman, M.S., Pentland, B.T., 2003. Reconceptualizing organizational routines as a source of flexibility and change. Adm. Sci. Q. 48, 94-118.

Feldman, M.S., Rafaeli, A., 2002. Organizational routines as sources of connections and understandings. J. Manage. Stud. 39, 309-331.

Feldman, M.S., Pentland, B.T., D’Adderio, L., Lazaric, N., 2016. Beyond routines as things: introduction to the special issue on routine dynamics. Organ. Sci. 27 (3), 505-513.

Feldman, M.S., 2000. Organizational routines as a source of continuous change. Organ. Sci. 11, 611-629.

Felin, T., Foss, N.J., Heimeriks, K.H., Madsen, T.L., 2012. Microfoundations of routines and capabilities: individuals, processes, and structure. J. Manage. Stud. 49 (8), 1351-1374. 
Gavetti, G., Levinthal, D., 2000. Looking forward and looking backward: cognitive and experiential search. Adm. Sci. Q. 45, 113-137.

Gavetti, G., Levinthal, D., Ocasio, W., 2007. Neo-Carnegie: the Carnegie School's past, present, and reconstructing the future. Organ. Sci. 18 (3), 523-536.

Gavetti, G., 2005. Cognition and hierarchy: rethinking the microfoundations of capabilities' development. Organ. Sci. 16 (6), 599-617.

Gioia, D.A., Price, K.N., Hamilton, A.L., Thomas, J.B., 2010. Forging an identity: an insider-outsider study of processes involved in the formation of organizational identity. Adm. Sci. Q. 55, 1-46.

Gioia, D.A., Corley, K.G., Hamilton, A.L., 2013. Seeking qualitative rigor in inductive research notes on the Gioia methodology. Organ. Res. Methods 16 (1), 15-31.

Glaser, V.L., 2017. Design performances: how organizations inscribe artifacts to change routines. Acad. Manage. J. 60 (6), 2126-2154.

Gupta, A., Hoopes, D.G., Knott, A.M., 2015. Redesigning routines for replication. Strateg. Manage. J. 36, 851-871.

Helfat, C.E., Peteraf, M.A., 2003. The dynamic resource-based view: capability lifecycles. Strateg. Manage. J. 24, 997-1010.

Helfat, C.E., Winter, S.G., 2011. Untangling dynamic and operational capabilities: strategy for a (n)ever-changing world. Strateg. Manage. J. 32, 1243-1250.

Howard-Grenville, J., Rerup, C., 2016. A process perspective on organizational routines. In: Langley, A., Tsoukas, H. (Eds.), The Sage Handbook of Process Organization Studies. Sage Publications Limited, London, pp. 323-339 Chapter 20.

Howard-Grenville, J., Rerup, C., Langley, A., Tsoukas, A., 2016. Introduction: advancing a process perspective on routines by zooming out and zooming. In: Langley, A., Tsoukas, H. (Eds.), Organizational Routines: How They Are Created, Maintained, and Changed. Oxford University Press, Oxford, pp. 1-18 Chapter 1.

Jarzabkowski, P.A., Lê, J.K., Feldman, M.S., 2012. Toward a theory of coordinating: creating coordinating mechanisms in practice. Organ. Sci. 23, 907-927.

Jensen, R.J., Szulanski, G., 2007. Template use and the effectiveness of knowledge transfer. Manage. Sci. 53, 1716-1730.

Jick, T.D., 1979. Mixing qualitative and quantitative methods: triangulation in action. Adm. Sci. Q. 24, 602-611.

Jonsson, A., Foss, N.J., 2011. International expansion through flexible replication: learning from the internationalization experience of IKEA. J. Int. Bus. Stud. 42, 1079-1102.

Kelle, U., 2005. Emergence vs. forcing of empirical data? A crucial problem of grounded theory reconsidered. Forum Qualitative Sozialforschung/Forum: Qual. Soc. Res.

Knott, A.M., 2001. The dynamic value of hierarchy. Manage. Sci. 47 (3), 430-448.

Kumar, N., Stern, L.W., Anderson, J.C., 1993. Conducting interorganizational research using key informants. Acad. Manage. J. 36, 1633-1651.

Langley, A., 1999. Strategies for theorizing from process data. Acad. Manage. Rev. 24 691-710.

Lazaric, N., Denis, B., 2005. Routinization and memorization of tasks in a workshop: the case of the introduction of ISO norms. Ind. Corp. Change 14 (5), 873-896.

Lazaric, N., 2011. Organizational routines and cognition: an introduction to empirical and analytical contributions. J. Inst. Econ. 7 (2), 147-156.

Levinthal, D., Marino, A., 2015. Three facets of organizational adaptation: selection, variety, and plastcity. Organ. Sci. 26 (3), 743-755.

Levinthal, D., Rerup, C., 2006. Crossing an apparent chasm: bridging mindful and lessmindful perspectives on organizational learning. Organ. Sci. 17 (4), 502-513.

Levitt, B., March, J.G., 1988. Organizational learning. Ann. Rev. Sociol. 14, 319-340.

Lincoln, Y.S., Guba, E.G., 1985. Naturalistic Inquiry. Sage.

March, J., Simon, H.A., 1958. Organizations. Wiley, New York.

March, J.G., 1991. Exploration and exploitation in organizational learning. Organ. Sci. 2, 71-87.

McDonald, C.J., 1998. The evolution of Intel's Copy EXACTLY! technology transfer method. Intel Technol. J. 4, 1-6.

Nelson, R.R., Winter, S., 1982. An Evolutionary Theory of Economic Change. Harvard University Press, Cambridge, MA.

Nicolini, D., 2009. Zooming in and out: studying practices by switching theoretical lenses and trailing connections. Organ. Stud. 30 (12), 1391-1418.

Obstfeld, D., 2012. Creative projects: a less routine approach to getting new things done. Organ. Sci. 23 (6), 1571-1592.

Parmigiani, A., Howard-Grenville, J., 2011. Routines revisited: exploring the capabilities and practice perspectives. Acad. Manage. Ann. 5, 413-453.

Peeters, C., Massini, S., Lewin, A.Y., 2014. Sources of variation in the efficiency of adopting management innovation: the role of absorptive capacity routines, managerial attention and organizational legitimacy. Organ. Stud. 35, 1343-1371.

Pentland, B.T., Feldman, M.S., Becker, M.C., Liu, P., 2012. Dynamics of organizational routines: a generative model. J. Manage. Stud. 49 (8), 1484-1508.

Peteraf, M., Di Stefano, G., Verona, G., 2013. The elephant in the room of dynamic capabilities: bringing two diverging conversations together. Strateg. Manage. J. 34, 1389-1410.

Rerup, C., Feldman, M.S., 2011. Routines as a source of change in organizational schemata: the role of trial-and-error learning. Acad. Manage. J. 54, 577-610.

Salvato, C., Rerup, C., 2011. Beyond collective entities: multilevel research on organizational routines and capabilities. J. Manage. 37, 468-490.

Salvato, C., Rerup, C., 2018. Routine regulation: balancing conflicting goals in organizational routines. Adm. Sci. Q. 63 (1), 170-209.

Seele, K., Grand, S., 2016. Unpacking the dynamics of ecologies of routines: mediators and their generative effects in routine interactions. Organ. Sci. 27 (3), 722-738.

Spee, P., Jarzabkowski, P., Smets, M., 2016. The influence of routine interdependence and skillful accomplishment on the coordination of standardizing and customizing. Organ. Sci. 27 (3), 759-781.

Strauss, A., Corbin, J., 1990. Basics of Qualitative Research: Grounded Theory Procedures and Techniques. Sage, Newbury Park, CA.

Strauss, A.L., 1987. Qualitative Analysis for Social Scientists. Cambridge University Press.

Suddaby, R., 2006. From the editors: what grounded theory is not. Acad. Manage. J. 49, 633-642.

Szulanski, G., Jensen, R.J., 2006. Presumptive adaptation and the effectiveness of knowledge transfer. Strateg. Manage. J. 27, 937-957.

Szulanski, G., Jensen, R.J., 2008. Growing through copying: the negative consequences of innovation on franchise network growth. Res. Policy 37, 1732-1741.

Teece, D.J., Pisano, G., Shuen, A., 1997. Dynamic capabilities and strategic management. Strateg. Manage. J. 18, 509-533.

Teece, D.J., 2007. Explicating dynamic capabilities: the nature and microfoundations of (sustainable) enterprise performance. Strateg. Manage. J. 28, 1319-1350.

Turner, S.F., Rindova, V., 2012. A balancing act: how organizations pursue consistency in routine functioning in the face of ongoing change. Organ. Sci. 23 (1), 24-46.

Van Maanen, J., 1979. The fact of fiction in organizational ethnography. Adm. Sci. Q. 24, 539-550.

Winter, S.G., Szulanski, G., 2001. Replication as strategy. Organ. Sci. 12, 730-743.

Winter, S.G., Szulanski, G., Ringov, D., Jensen, R.J., 2012. Reproducing knowledge: inaccurate replication and failure in franchise organizations. Organ. Sci. 23, 672-685.

Winter, S.G., 1995. Four Rs of profitability: rents, resources, routines, and replication. In: Montgomery, C. (Ed.), Resource-based and Evolutionary Theories of the Firm: Towards a Synthesis. Springer, pp. 147-178.

Winter, S.G., 2003. Understanding dynamic capabilities. Strateg. Manage. J. 49 (8), 1402-1406.

Zollo, M., Winter, S.G., 2002. Deliberate learning and the evolution of dynamic capabilities. Organ. Sci. 13, 339-351. 